\title{
A Critical Literary Review of the Melting Pot and Salad Bowl Assimilation and Integration Theories
}

\author{
Mohamed Berray ${ }^{1}$ \\ Florida State University, FL, USA
}

\begin{abstract}
Immigrant communities have varying degrees of acculturation based on their predispositions for specific cultural norms and their propensity to exhibit similarities in principles, values, and a common lifestyle with dominant racial and ethnic groups. Food metaphors like the Melting Pot and the Salad Bowl theories have illustrated different approaches to integration by explaining the political and power dynamics between dominant and minority groups. Yet, little consideration is given in either theory to existing local contexts that influence the actions of these groups. By combining ethnic identities into homogenous outcomes, food metaphors empower dominant ethnic groups and set the tone for discriminatory legislative policies that eliminate programs aimed at helping minorities. For refugees, this obscures their actual socio-political circumstances and erases their historical experiences. This paper aims to review and critique existing literature about metaphorical homogenous assimilation and integration theories, with experiences from around the world. This paper postulates that using a homogenous common good as the baseline metaphor for assimilation and integration disregards the individual accommodations that need to be made for both dominant and minority communities. These accommodations, although sometimes separate from the collective good, have a significant role in creating conducive environments for diversity and inclusion.

Keywords: integration, ethnicity, identity, melting pot, Salad Bowl, assimilation.
\end{abstract}

\section{Introduction}

People are not food. Vague food metaphors transmit racist views and perpetuate disparities in interpretation (Gloor, 2006; López-Rodríguez, 2014). Although these metaphors have helped explain current political and power dynamics between dominant and minority groups, it is unclear what their applications are through specific legislative and social actions at the national level. The main disadvantage of food metaphors proposed in this paper is that combining ethnic identities into homogenous outcomes empowers dominant groups to believe that minorities are closer to them than they are to their countries/cultures of origin. This lack of cultural sensitivity victimizes minority groups through inappropriate mainstream cultural commentary and assertions with the expectations of common understanding and lack of recourse on the part of minority groups. Even when true integration happens, each individual retains a significant portion of their cultural origin that is not easily lost. Coercive policies to homogenize identities in the Melting Pot theory makes it both difficult, and in some instances impossible, to achieve the intended assimilation of minority ethnic groups in host societies. The fear of losing one's native culture as a price for integration is sometimes is a price too heavy to pay. Instead of food metaphors, we need inclusive theories that coalesce discordant viewpoints of diverse societies into admissible heterogeneity practices of the represented groups.

\section{The Melting Pot Theory}

The Melting Pot theory first rose to prominence when in 1782, J. Hector St. John de Crevecoeur, an immigrant from France, described the demographic homogeneity of the United States as comprising "individuals of all nations....melted into a new race of men, whose labors and posterity will one day cause great changes in the world" (St. John de Crevecoeur, 1782, para. 5). In his view, Americans are "western pilgrims" who carry with them industrial skills from the East, and will finish the great circle of their pilgrimage in the United States. According to Laubeova (2005), St. John de Crevecoeur envisioned a prosperous American labor force comprised of new races with greater influence on U.S. standing on the world stage.

Almost a century later in 1845, Ralph Waldo Emerson, a poet who led the American transcendentalist movement of the mid-19th century, expanded on St. John de Crevecoeur's theory by describing America as "the Utopian product of a culturally and racially mixed smelting pot" (Emerson et al., 1971, p. 116). In 1875, an article by Titus Munson Coan, in his attempt to describe the smelting process of becoming an American,

\footnotetext{
${ }^{1}$ Correspondence: Social Sciences Librarian for Political Sciences, Public Policy, International Affairs. Coordinator for Government Information, Florida State University Libraries, 0027L Strozier Library | 116 Honors Way | Tallahassee, FL 32306 | E-mail: mberray@fsu.edu.
} 
introduced the Melting Pot theory as the fusing of individualities, including any traits of immigrant religion and race, down a blast furnace in a "democratic alembic like chips of brass in a melting pot" (Coan, 1875, p. 463).

The Melting Pot theory was further popularized in 1908 by Israel Zangwill's Broadway production, "The Melting Pot", about two lovers from Russian Jewish and Russian Cossack families. A character in the play, David, says "America is God's crucible, the great melting-pot where all the races of Europe are melting and reforming" (Zangwill, 1921, p. 33). Zangwill was referring specifically to the idea that America is a country where it is pointless and almost impossible for immigrants - the Germans and French, the Irish and English, and Jews and Russians - to continue their feuds and hatred. For the new immigrants, it was pointless, unfavorable, and to some extent impossible, for them to nourish their animosity and prejudices towards one another. This impetus to assimilate was described by Wagener (2009) as an adaptation of minority groups to the cultural norms and "structural characteristics" of the culturally, politically, and economically dominant group (p.3). This adaptation to dominant norms reduces linguistic and cultural differences between ethnic minorities and host communities with the expectations of integration into mainstream society. The newly formed integrated society consists of pre-existing identities in association with newly introduced forms (Calderon Berumen, 2019). It involves blending lifestyles between immigrants and hosts, converging within and among themselves to a common lifestyle that continues to evolve over time (Meier, 2019; Park \& Burgess, 1924; Woofter, 2019).

Though heavily criticized, especially by alternate integration and assimilation theories like the Salad Bowl, the Melting Pot theory has its advantages. First, it consolidates the concept of citizenship by creating an environment that integrates different ethnicities to celebrate national pride under a single banner. As said by Miller (2005), "citizenship provides a reference point. Our personal lives and commitments may be very different, but we are all equally citizens, and it is as citizens that we advance claims in the public realm and assess the claims made by others" (p. 41). By expanding citizenship, the Melting Pot theory, by extension, also expands national identity to be inclusive of different ethnicities and the values they bring with them. Secondly, it removes the singular homogenous identity attached to nation states, i.e., one federal government, a single national flag, defined territory, singular passport, all of which can be extended to mean a single national identity. The Melting Pot theory redefines this concept and solidifies the idea that national identity can be made up of multiple identities fused together under a single national emblem. In other words, it promotes a sense of community and social solidarity.

Citizenship provides a formidable compromise to integration because it is conferred not by a measure of deviation or replacement of one's cultural values from their countries of origin, but by a measure of adaptation to the laws and values in host societies (Lafer \& Tarman, 2019). In the United States for example, the U.S. Congress passed a joint resolution in 1940 requesting that the President of the United States issue an annual proclamation declaring the 3rd Sunday in May each year as "I Am An American Day" (54 Stat. 178) in recognition of all who had attained American citizenship. Although this resolution was repealed in 1952, a new law was passed designating September 17 as "Citizenship Day" to recognize those who have attained American citizenship, and to commemorate "the formation and signing, on September 17, 1787, the Constitution of the United States" (66 Stat. 9). A 2004 amendment to the Omnibus Spending Bill later declared September 17 as Constitution Day and Citizenship Day (36 U.S. Code $\S 106$ ).

When immigrants naturalize in the United States, they swear to support the Constitution and renounce and abjure absolutely and entirely all allegiance and fidelity to any foreign prince, potentate, state, or sovereignty of whom or which the applicant was before a subject or citizen (8 U.S. Code § 1448). Upon attainment of U.S. Citizenship, immigrants still retain their cultural and personal values of their countries of origin. Attainment of U.S. Citizenship, therefore, welcomes immigrants to the United States, whilst granting them the opportunity to retain their individuality, including practicing their faith and cultural beliefs of their countries of origin. The Melting Pot theory will therefore continue to hold value as an allegory for national unity so long as substituent ethnicities are recognized and ethnic multiplicity is considered an essential component within U.S. citizenship.

\section{The Salad Bowl Theory}

Starting in the 1960s, a new vision of American pluralism arose metaphorically similar to the salad bowl (Thornton, 2012). Compared to the melting pot, the Salad Bowl theory maintains the unique identities of individuals that would otherwise be lost to assimilation. The immediate advantage of the Salad Bowl theory is that it acknowledges the discrete identities and cultural differences of a multicultural society. This appreciation for the individual contributions of each ethnic group to society transcends the overarching ascendance of the dominant culture at the expense of imperceptible minority groups. Contrary to the Melting Pot theory where the identity and influence of the dominant ethnic group prevails regardless of the transformation resulting from the assimilation and cultural morphology, the Salad Bowl retains the individuality and independence of ethnic groups, and permits their existence side-by-side dominant cultures. This removes the pressure to create 
homogenous identities in the Melting Pot theory, especially since such homogenous identities are not representative in equal proportion of their constituent identities.

The Salad Bowl theory, given its shortcomings, provides more integrative possibilities than the melting pot. Metaphorically speaking, we can be selective with the ingredients we add to our salad, leaving some out, and increasing the amounts of others based on our needs. Thus, not only does the salad bowl metaphor allow for the individuality of ethnic identities it represents, but it also paves the way for selective integration between ethnic groups based on their need to integrate in host societies. This advantage of the Salad Bowl theory holds important application to immigrant communities giving their different propensity to integrate based on their predispositions for specific cultural norms and lifestyles in their host societies. According to Wagener (2009), people with a common lifestyle will "belong to the same social milieu if their ways of life, principles, norms and values exhibit similarity" (p. 5). Therefore, any attempts by assimilation policies at narrowing differences and dissimilarities in lifestyles between immigrants ad dominant societies are in fact contingent on measures that are relative to exogenous and endogenous reference standards in the host country (Wagner, 2009). This approach can be intrinsically misplaced. Take race and language as examples: culturally dominant societies of the same race who speak the same language can be fundamentally different in their values and norms (Tarman \& Gürel, 2017). Immigrants of different races who do not speak the dominant language but with similar predispositions in their countries of origins can share values predominant in their host societies. Foner (2000) explained this using the example of Jamaican women in New York with higher employment rates than Dominicans. This is because Jamaicans have English language expertise and slightly higher educational levels. But also, Jamaican society has a strong tradition of female employment, unlike Dominicans where women have traditionally withdrawn from the workforce to symbolize their household's respectability and elevated economic status (Foner, 2000). Similar observations have been attributed to the successes of Asian students, where cultural factors play a significant role in shaping parents' expectations, including enrolment in after-school institutions that "prepare Korean and Chinese children for exams in the city's specialized high schools" (Foner, 2000, p.258). Acceptance of these diverse values as integral to host societies can help bridge the gap, rather than exclusive policies that aim of preserving dominant cultures at the expense of integration. According to Borjas (1994), immigrants with high levels of productivity that rapidly adapt to host country conditions play a role in significantly improving the economy, lending him to appeal to natives that they "need not be concerned about the possibility of these immigrants [increasing] expenditures on social assistance programs" (p. 1667).

\section{Critiques of Metaphorical Assimilation and Integration Theories: The Melting Pot and the Salad Bowl}

There are many critiques of the Melting Pot theory. It's an "Anglo-conformist classic assimilation theory" (Brown \& Bean, 2006, online) that expects minority cultures to morph into a society with norms, values, and behaviors that reflect the dominant culture. In other words, people of different cultures combine so as to "lose their discrete identities and yield a final product of uniform consistency and flavor, different from the original inputs" (Gloor, 2006, p. 29). This unnecessary burden of expectation imposes on both the dominant and the minority culture the need to converge, becoming more similar over time (Kivisto, 2004). Not only is such an expectation unrealistic, it sets the tone for discriminatory legislative policies by eliminating programs aimed at helping minorities. According to Gloor (2006), such coercive assimilation policies induce fear into minorities seeking to preserve their heritage, and threaten to fracture the common ground social framework that holds the inclusive unity of groups that melting pot theorists claim to be protecting. Uniform ethno-morphological practices also do not allow for vital customizations to accommodate successful lifestyles of diverse citizens. This practice is widely observed in current media commentaries in light of racial tensions in America. The assertion that [we are all American] and claims that statements like [a black man being shot by police officer] is racially inflammatory, disempower the African American community to advocate against racial bias and discriminatory social policies that disenfranchises them. This logic minimizes the fact that we all belong to different races, with diverse and unequal historical experiences that cannot, and should not, be easily subsumed into a single American melting pot. At the end of the day, accumulated human dispositions that lead to defined cultural identities cannot be represented by ingredients used in a melting pot of cultures. The growth and development of social lifestyles and interactions, education, language, different means of survival, and upbringings are each separate components of our cultural identities that interact differently with different (dominant in this case) societies, and cannot be lost or assimilated in unison to (with) those of host societies.

A key shortcoming of the Melting Pot theory is that it ignores existing local contexts that influence the choices and actions of both dominant and minority groups, and the impacts of these on acculturation. It's important to note that when immigrants travel to the host countries, they do so with intent, and mostly, with the mindset of becoming integral to their new societies. When integration doesn't come easily, it is not always from refusal by immigrants to adapt to their new societies, nor is it always from fear, with the pretext that assimilation 
takes away from their preexisting cultural norms and values. Instead, as will be explained in upcoming sections, different immigrant communities have different propensities to integrate based on their predispositions for specific cultural norms and lifestyles from their host societies. It is also important in this context to distinguish assimilation from integration. According to Swaidan (2018), assimilation occurs when "individuals of the acculturating group choose to adopt the dominant culture" (p. 40). This view is supported by (Phinney, Horenezyk, Liebkind, \& Vedder, 2001) who described assimilation as taking place when a group views its own culture negatively and adopts the culture of the receiving society. Integration on the other hand, occurs when "there is an interest in both maintaining the original culture and simultaneously seeking to participate as an integral part of the dominant culture" (Swaidan, 2018, p.40). Integration therefore refers to the processes, and the systems and structures in place to allow minorities (immigrant groups) to attain opportunities afforded longterm citizens (Alba \& Foner, 2014), and other societal goals such as improved socioeconomic positions and inclusion in a broad range of societal institutions (Berry, 1997).

What immigrants ask for within their host societies, is the ability to integrate whilst retaining their cultural identities at birth. According to Gloor (2006), these could "serve as a compromise between full assimilation and multiculturalism" (p. 31), a dialogue that redefines the objective for multiethnic societies and allows for diversity and inclusion. This desire for immigrants to retain their cultures has been extensively researched and proven to be true. Bakker, van der Zee, and van Oudenhoven (2006) found that immigrant ethnic minorities prefer to retain aspects of their culture such as language, religion, and traditions as they integrate into host cultures. In many instances, this also includes forming social ties with other communities in exile with which they share similar characteristics. Even when similarities exist between immigrant communities and dominant host societies, the fear of losing one's native culture as a price for integration is sometimes seen as a price too heavy to pay. In many cases, dominant culture stereotypes that affiliate immigrants with existing minorities in the host society have forced immigrants to distinguish themselves by clinging to their cultures and emphasizing their linguistic and traditional characteristics that set them apart. This distinguishing behavior has been observed in Spanish-speaking immigrants who do not want to be confused with Puerto Ricans, and in darkskinned Indian immigrants who might be confused with African Americans (Foner, 2000). Bertsch (2013) also studied European immigrants who bear resemblance with their American counterparts and concluded that although they identify as Americans based on their residence in the United States, they do not readily assimilate because in doing so, they might lose valued cultural characteristics from their countries of origin. This differentiation of ethnic groups, and the creation of a bounded conceptual space to self-identify, also lies at the heart of the definition of ethnic identities. According to Ahmed (2016), ethnic identities are defined as the "aspect of a person's self-conceptualization which results from identification with a broader group in opposition to others on the basis of perceived cultural differentiation and/or common descent" (p. 2). Ethnic thickness, as it is called, refers to a strong sense of commitment to one's ethnic group. A looser sense of commitment has been termed ethnic thinness (Cornell \& Hartmann, 2007). Ahmed's definition is derived from Jones (1997) who defined an ethnic group as "any group of people who set themselves apart and/or are set apart by others with whom they interact or co-exist on the basis of their perceptions of cultural differentiation and/or common descent" (p. xiii).

This tendency of cultural fusion in the Melting Pot theory shares a striking similarity with the Salad Bowl theory that has also not been discussed in the literature. Similar to the literal meaning of a melting pot, a salad bowl is a combined dish, rather than the attention to the individual vegetables. In both theories, the final product is different from the individual ingredients. They both promote the idea of a culmination, and the coming to life of a finished meal, rather than highlighting the ingredients. Both theories focus on the end products of assimilation, and not the processes that lead to it. The end products - "melting pot" and "salad bowl" - are also defined in strict configurations, leaving little chance to deviate from the "recipe". It is clear in the Melting Pot theory that ingredients representing individual identities in the recipe are lost to the dominant identity base. A can of tomato soup will still preserve its dominant identity regardless of the composite additions to it. To also expect that integration and assimilation happens in a manner that resembles cooking a meal, is itself biased based on our cultural understandings of those meals.

This raises an important point. Like the melting pot, the salad bowl is a derivative process. In real life, this refers to the coexistence of different ethnicities side-by-side in peace and harmony with shared cultural and identity practices that serve their common good. The problem with using the "common good" as a conclusive baseline metaphor of assimilation is that they disregard the individual accommodations that need to be made for both dominant and minority communities. These accommodations, as much as they seem separate from the collective good, have a significant role in creating conducive environments for diversity and inclusion. Yet, in many instances, the inter-bonding between minority groups and the dominant counterpart is preferred and 
antecedent to the intra-bond that exist within a minority group, and between one minority group and another. The next section of this paper addresses this.

\section{Selectivity in Integration: The Case of Ethnicity in Exile}

The field of migration and refugee studies has studied the bond between different groups in exile in more detail. This socio-anthropological theory called ethnicity in exile postulates that the existing local contexts of host countries influence the choices and actions of immigrant groups from different origins. The definition of ethnicity used in this context is derived from Berry (1997) who defined ethnicity as the manifestation of "social and psychological phenomena associated with a culturally constructed group identity" (p. xiii). This is important because, as put by Ahmed (2016), the formation of ethnicity requires an interaction of social and cultural processes.

The Case of Refugees: Many researchers have studied the interaction of social and cultural processes and the effects of altering their natural occurrences. Moro (2004) studied interethnic relationships between Sudanese and Ugandan refugees in Egypt. His research proved that the diversity of people with different histories living in the same location influenced the relations of ethnic groups, sometimes for the better (Moro, 2004). Malkki (1995) studied how refugees from different ethnic groups in former Yugoslavia have reshaped their identities based on existing local contexts in different host countries. The findings of her research are that structural factors in the host countries of the refugees influence their experiences and shape their ethnic identities. Malkki's research demonstrates that domestic policies and practices in host countries with dominant ethnic groups create conditions that resulted in ethnic boundaries having little meaning in influencing the formation of identities and the social enterprise of refugees from the post Yugoslav states. This view is supported by Ahmed (2016) who described the boundaries between ethnic groups to be as much psychological as cultural and social, and has to be understood in intergroup perspectives. Specifically in the case of refugees, their common needs usually places them in contrast with resident dominant groups and characterizes them with distinct identities. In many cases, these immigrants find themselves living with other minorities, including native-born minorities. As a result, they join together to pursue common goals, sometimes in the face of common discrimination and prejudice (Foner, 2000). What this means is that conditions of exile may in fact augment and strengthen the formation of social networks between different ethnic groups to help enhance their integration in new societies. According to Korac (2004), these constructions of ethnic and identity processes leveraged by the conditions of settlement in host countries are pivotal to addressing the sociopolitical consequences of the displacement of people fleeing ethnic strife. This in return influences successful post-conflict rehabilitation and reconstruction of war-torn societies, contingent on facilitated settlement experiences and reshaped identity processes of repatriates.

Seclusion of Dominant Groups: The advantage of extending the theoretical underpinnings of ethnicity in exile as a vantage point in filling the shortcomings of both the Salad Bowl and the Melting Pot theories is that they also both apply to the acceptance of dominant ethnic groups by minorities. Many times, dominant ethnic groups, including whites in the United States, have been stereotyped for their racial seclusiveness. These social racial groupings, such as the "redneck", have been criticized as conservative and racially segregationist. However, their social lifestyles alone do not amount to racism, except if done with discriminatory intent. Such stereotypical characterizations of rednecks further exposes the misplacement of ethnic differentiation that has been impressed on ethnic minorities. The reality is redneck is a pejorative term for lower class working white people dating back to the indentured servitude of farm workers throughout the South and the Caribbean colonies. During those times, the whiter the skin, the richer and more refined the individual. Having a literal redneck meant a field worker and thus a lower class.

According to Huber (1995), one of the earliest use of the name "redneck" was in 1893 when Hubert A. Shands reported that the word was used by upper class [whites] in Mississippi to distinguish themselves from poorer residents of rural districts. The word later entered the political discourse of the State in the 1980s when "Democrats used it to denigrate farmers within their party who supported populist reforms" (Ferguson, 1953, p. 519). Since then the pejorative term has been used to denigrate the rural poor "white of the American South and particularly one who holds conservative, racist, or reactionary views" (Huber, 1995). By the mid-sixties, the connection between redneck and racism was firmly cemented, especially for African Americans (Huber, 1995). The group originally meant still exists, but not in the socially constructed way it is used now. These folks that it truly represents have been relegated to the ultra-poor Appalachia (see Shelby, 1999) and rust belt of the Midwest, and are fundamentally different than the original group the term was assigned to.

Dominant ethnic groups deserve to support political ideologies of their choosing, including be conservative, live in suburbs, and drive pickup trucks and other vehicles of their choosing without exposing themselves to rigorous stereotypical critiques as those that have befallen rednecks. Enjoying the rights and 
privileges of free and democratic societies should not come as a trade-off based on the compromise of one's identity. For this to be true, it should apply to all peoples, including minority groups who wish to coexist with one another, without risking aspects of their cultures for fear of being told that they are unwilling to integrate. In other words, integration should not be a measure of the degree of bond that exists between dominant and minority groups in multiethnic societies, nor should it be a measure of how much ethnic minorities dissociate themselves from the cultural practices, beliefs, and values of their countries of origin. This static versus dynamic approaches to ethnicity and acculturation has been brilliantly explained by Ahmed (2016) and Jones (1997) who said that static perspectives, otherwise known as primordial approaches to integration, emphasize the bonds that exist between individuals in a group at birth that are mostly involuntary and as a result possess a stigma of coerciveness that transcends the alliances and relationships engendered by situational interests and social circumstances. According to Jones (1997), these primordial attachments resist nationalizing immigrants because it provides a "natural and fundamental form of identity than other forms of social identity" (p. 66). This explains why, according to Glazer (2000), discussions of cultural differences have been avoided in the United States since they may communicate that some cultures are better than others. The risks of pursuing these discussions sometimes outweigh the gains, and may be of little long-term significance as compared to the melting pot, which attenuates cultural differences (Bertsch, 2013). This is however ironic in the United States where the U.S. Census Bureau projects a significant decline in the white population by 2035. According to Alba \& Foner (2014), the number of Americans between the ages of 16-64 is expected to drop by 20 million by 2035 . What this all means is that, instead of focusing on the loss or dilution of identities as a measure of adaptation in new societies, integration could be a measure of the successes of immigrants to capitalize on the systems and structures of their new society, to learn to use them for their advantage, and to derive economic and individual success whilst at the same time contributing to society. Acculturation could be a bidimensional process in which immigrants' retention of their cultural heritage and acquisition of dominant group identities are not placed at extreme ends of the spectrum.

Enhancing Integration By Meeting Immigrant Needs: Both the Melting Pot and the Salad Bowl theories spend too much time defining the different possible configurations of integration, and the potential outcomes, based on each configuration type. This overemphasis on whether assimilation through the melting pot is preferred even if it means loss of individual identity or whether integration through the Salad Bowl means better co-existence and retention of ethnic identity, misses out on true needs of ethnic minorities, and opportunities that could be created to enhance their integration. This recognition of the needs of immigrant communities and the necessary efforts in meeting those needs that allow them to thrive is a key advantage of the Ethnicity in Exile theory. The underlining principle in the Ethnicity in Exile theory is that by strengthening the bonds between immigrant communities, we allow the experiences and the successes of established mutigenerational immigrant communities to become part of the settlement experiences of new immigrants. These established communities provide help and aid the transition and establishment of new members of their community. According to Ahmed (2016), ethnic groups that are strong in absolute numbers, recognition in terms of language and economic prestige, have a high vitality, thus ensuring collective survival and existence. On the other hand, overemphasis on immediate integration and assimilation between new immigrant communities and dominant ethnic groups builds resistance and takes away from the time needed to build relations that provide new immigrants with the tools needed to succeed.

Selectivity and Duality: The one advantage that the Ethnicity in Exile theory holds over other integration theories is the concept of selectivity and duality. In duality, members of an immigrant community simultaneously exist as members of their ethnic group, and as members of their new community, co-existing with dominant ethnic groups. Duality proffers a non-static perpetually changing conception of ethnicity (Ahmed, 2016). Referred to as "metroethnicity" by Maher (2005), duality is a "hybridized ethnicity" deployed by people who are oriented towards cultural hybridity, cultural/ethnic tolerance and a multicultural lifestyle" (Maher, 2005, p. 83). In selectivity, they chose which ethnic communities they interact with based on the similarities that exist between ethnic groups. In both the selectivity and duality principle, dominant and minority ethnic groups exist as distinct ethnic groups living side by side and make individual choices about their needs, including which members of their communities they engage with. Selectivity in ethnicity strengthens bonds and holds the unique advantage for economic opportunities for immigrant communities. Giving the commonalities that exist between similar ethnic groups, selective integration makes it easy to achieve successes in their host societies that could serve as the steppingstone for further integration.

Formation of Heterogeneous Communities: Advani \& Reich (2015), in their research about the formation of heterogeneous communities, talked about the critical mass required to sustain heterogeneous integrative outcomes. The conclusions of their research is that the smaller the size of minority groups relative to the size of the majority, assimilation occurs easily. However, when the population of minority groups is large 
enough to attain a critical mass threshold, then there exists the tendency for these minority groups to maintain their distinct cultures, especially when the cost of switching cultures outweighs the benefits of intragroup bonding within their communities. Of course, the grounding of the critical mass threshold theory depends on the similarities between minority groups, and the relevance of their intercultural similarity to meeting everyday life needs. The strength or weakness of that similarity is the equivalent of the cost of forming social ties, a theory similar to ethnicity in exile. Advani \& Reich (2015) tested the effects of strengths and weaknesses on ethnic bonding using data on mass migration to the United States in the early $19^{\text {th }}$ Century and found it true that "above a certain critical mass of migrants, structure in heterogeneous populations changes discreetly towards cultural distinction and segregation" (p.3). The reality is many minority communities, including immigrants, face a tradeoff between maintaining and sustaining their cultural values, and economic incentives that require them to assimilate with dominant societies. Research on intercultural relations that aim to understand how individuals behave towards one another across ethnic lines have proven that acculturation-specific attitudes adopted by immigrant groups as a means to integrate is mostly dependent on the expectations held by dominant groups. For exactly this reason, Berry (2001) conceived multiculturalism as a society-level attitudinal expectation corresponding to individual-levels of acculturation strategy of integration. These acculturation expectations sometimes parallel the acculturation strategies among non-dominant peoples and plays a role in intercultural relations between the two (Hui, Chen, Leung, \& Berry, 2015).

\section{Conclusion}

In her popular essay, Wagener (2009) made a distinct point that "assimilationist policies do not have assimilationist outcomes but integrative policies do" (p. 15). The reason for this is that integration evens out lifestyle differences where dominant-culture approaches fail. On the other hand, when assimilation is imposed, it provokes resistance. Even though both members of the immigrant and dominant groups experience aspects of cultural exchange in their daily interactions, the burden to integrate is mostly on the minority group as they are required to adopt skills in socioeconomic domains to survive. Dominant cultures who belong by birth to these societies do not have the same expectations (Hui et al., 2015). It is immigrants who have to integrate themselves at the expense of equity in fulfilment of integration expectations of dominant groups, which sometimes outweigh multicultural perspectives. According to Brubaker (2001) "when it [assimilation] is forcefully implemented, it provokes mobilization against its pressures" (p. 534). Chiswick (2009) interprets some of this as "a reflex of strong social disapproval of cultural hegemony or even elitism, over lifestyles, and adds to "cultural relativism'" (p. 864). The bottom line is, there is no easy way to perpetuate or reproduce homogenous societies with blended cultural values that succeed existing norms of dominant host societies. Doing so ignores the value of preserving cultural differences in society. In times like these, we need a new dialogue that defines the parameters for multiethnic societies and allows for diversity and inclusion of represented ethnic groups. These ethnic groups should not have to face a trade-off between retaining and preserving their cultural values, associating with, and getting involved in community engagements as they relate to their cultural heritage and practices, and full participation in the economic activities of mainstream society. Societies that strive to be multicultural should create incentives and opportunities to engage with the full spectrum of identities within their midst. Recognition of ethnic minority values and the opportunities to integrate cultural practices in day-to-day life will reduce the cost of tradeoff between forming social ties among immigrant and minority communities, and full participation in the economic and social life of their communities. This was found to be true in Germany and Switzerland where Pionkowski, Rohmann, and Florack (2002) found that dominant groups had strong preferences for integration when a positive relationship was anticipated with ethnocultural groups and when they perceived similarities with them.

Cultural pluralism or multiculturalism has been touted as desired more than assimilative theories and principles. Multiculturalism includes mutual respect for cultural differences and active support for equal chances among dominant and non-dominant groups (Hui et al., 2015). In the 1970s, most countries, including, the United States, Australia, and Canada, rejected assimilationist models and adopted pluralistic policies that allowed immigrants and minorities to maintain aspects of their cultural heritage, without being deemed unpatriotic (Kymlicka, 1995). This approach allows the "ingredients" in the melting pot or the salad bowl to retain their identity through cultural preservation and contribute to society without abandoning unique cultural lifestyles in the name of assimilation. This view has also been supported by social identity theorists who have suggested that integration yields best results because it allows immigrants to maintain a common identity with host societies while being able to distinguish themselves (Hui et al., 2015). This is the case in many parts of the world. In Europe for example, data of European Union immigrants in France, Germany, and the Great Britain reveal that immigrants prefer integration as a way to acculturate (Swaidan, 2018). The same is true of Jewish youth in Russia (Tartakovsky, 2002), Asian-Americans (Swaidan, 2018), and Indian immigrants (Krishnan \& Berry, 
1992). In the United States, 37.5\% of Middle Eastern professionals prefer integration (Alkhazraji, Gardner, Martin, \& Paolillo, 1997). In all cases, immigrants preferred to preserve their traditions, language, religion, and social connections, whilst trying to acculturate in host societies. Nguyen \& Benet-Martínez (2013) also produced a strong body of evidence that demonstrates that acculturation is best achieved through multicultural integration.

In a pure nationalistic sense, being a citizen of a country is not tied to a single culture. If anything, normative multicultural policies adds value and celebrates diversity and inclusion without loss of uniqueness. Instead of forging ways that society should look like itself, we should focus on increasing interaction and communication between different cultural identities and practices and celebrate differences and cultural uniqueness. According to Ahmed (2016) "integration takes place when a group shows positive response to its own cultural heritage as well as develops good relationship with the receiving society" (p.1). The United States, according to Lichter (2013), has moved well beyond the "melting pot" metaphor and has instead embraced a new multiculturalism, while also acknowledging the possibility of segmented assimilation and transnationalism. The Netherlands, Sweden, and the United Kingdom are also deemed good examples of integration (Pasetti, 2019). The economies of these countries have helped in integrating immigrants. In the European social market economy where the economy is more heavily regulated by the state, government social benefits have protected immigrants against the vagaries of the labor market (Alba \& Forner, 2014). In many of these countries, especially in Germany, France, and the Netherlands, there are state-mandated procedures that employers must follow, including payment of severance packages. This has protected immigrant from falling into poverty and ensuring that they have the financial means to live decent lives (Alba \& Forner, 2014). In the United States and other liberal market economies, especially in Canada and the UK where immigrants are not exposed to similar state-sponsored safety net structures, these immigrants are forced to take jobs that retain a lower socioeconomic status. However, according to Alba \& Foner (2014), even in these situations at the low end of the labor market, employment offers a degree of integration with the potential of developing useful social networks and skills that maybe useful for the future. The United States, however, has distinct advantages over its European counterparts since it is a settler country. The underlying assumption, according to Alba \& Foner (2014) is that settler societies founded by immigrants are more successful in integrating immigrants. European countries on the other hand, have more exclusive national identity narratives, and were not open to mass immigration until after the creation of nation states. The conclusions of this is that different socioeconomic and heritage structures shape the willingness of nations to recognize immigrants as people with distinct needs and cultural right. It also means that societies where both dominant and minority ethnic groups adopt mutual acceptance of their lifestyles, even where lifestyles differ across various spaces and ethnicities, are considered good and progressive and allows for all parties to contribute to societal good. Thusly, instead of focusing on the constant of commonalities between identities, we should agree that the communal constant is that no one ethnic, religious, or cultural value should define us. The use of national philosophies as expectations of integration, as relevant as they are, is not the baseline measures of successes of integration. It's only one consideration alongside a range of structural factors that make immigrants feel at home.

\section{References}

Advani, A., \& Reich, B. (2015). Melting pot or salad bowl: The formation of heterogeneous communities. IFS Working Paper W15/30, Institute for Fiscal Studies. doi:10.1920/wp.ifs.2015.1530

Ahmed, M. (2016). Ethnicity, identity and group vitality: A study of Burushos of Srinagar. Journal of Ethnic and Cultural Studies, 3(1), 1-10.

Alba, R., \& Foner, N. (2014). Comparing immigrant integration in North America and Western Europe: How much do the grand narratives tell us? International Migration Review, 48(1). doi:10.1111/imre.12134

Alkhazraji, K. M., Gardner, W. L, Martin, J. S., \& Paolillo, J. G. P. (1997). The acculturation of immigrants to U.S. organizations: The case of Muslim employees. Management Communication Quarterly, 11(2), 215-265. doi:10.1177/0893318997112003

Bakker, W., van der Zee, K., \& van Oudenhoven, J. P. (2006). Personality and Dutch emigrants' reactions to acculturation strategies. Journal of Applied Social Psychology, 36(12), 2864-2891. doi:10.1111/j.00219029.2006.00132.x

Berry, J. W. (2001). A psychology of immigration. Journal of Social Issues, 57(3), 615-631. doi:10.1111/00224537.00231

Berry, J. W. (1997). Immigration, acculturation, and adaptation. Applied Psychology, 46(1), 5-68. doi:10.1111/j.1464-0597.1997.tb01087.x

Bertsch, A. (2013). The melting pot vs. the salad bowl: A call to explore regional cross-cultural differences and similarities within the U.S.A. Journal of Organizational Culture, Communications and Conflict, 17(1), 131-148. 
Borjas, G. J. (1994). The economics of immigration. Journal of Economic Literature, 32(4), 1667-1717. Retrieved from http://www.jstor.org/stable/2728791

Brown, S. K., \& Bean, F. D. (2006). Assimilation models, old and new: Explaining a long-term process. Migration Policy Institute. Retrieved from https://www.migrationpolicy.org/article/assimilationmodels-old-and-new-explaining-long-term-process (accessed August 13, 2018).

Brubaker, R. (2001). The return of assimilation? Changing perspectives on immigration and its sequels in France, Germany, and the United States. Ethnic and Racial Studies, 24(4), 531-548. doi:10.1080/01419870120049770

Calderon Berumen, F. (2019). Resisting Assimilation to the Melting Pot:. Journal of Culture and Values in Education, 2(1), 81-95. Retrieved from http://cultureandvalues.org/index.php/JCV/article/view/25

Chiswick, C. U. (2009). The economic determinants of ethnic assimilation. Journal of Population Economics, 22(4), 859-880. doi:10.1007/s00148-008-0190-y

Coan, T. M. (1875). A new country. In The galaxy: A magazine of entertaining reading, 19(4) (January 1875 to June 1875), 462-472. New York: Sheldon \& Company. Retrieved from https://books.google.com/books?id=C0OgAAAAMAAJ\&lpg=PA472\&dq=Titus\%20Munson\%20Co an $\% 2 \mathrm{C} \% 20 \% 22 \mathrm{~A} \% 20 \mathrm{New} \% 20 \mathrm{Country} \% 22 \% 2 \mathrm{C} \% 20 \mathrm{The} \% 20 \mathrm{Galaxy} \& \mathrm{pg}=\mathrm{PA} 1 \# \mathrm{v}=$ onepage $\& \mathrm{q} \& \mathrm{f}=\mathrm{f}$ alse

"Constitution Day and Citizenship Day." Title 36 United States Code, Sec. 106. Retrieved from https://www.govinfo.gov/content/pkg/USCODE-2017-title36/pdf/USCODE-2017-title36-subtitleIpartA-chap1-sec106.pdf

Cornell, S., \& Hartmann, D. (2007). Ethnicity and race: Making identities in a changing world (2nd ed.). Thousand Oaks, CA: Pine Forge.

Emerson, R. W. et. al. (1971). Journals of Ralph Waldo Emerson with Annotations, 1845-1848 (vol. 7). E.W. Emerson, \& W. E. Forbes (Eds.). Cambridge: The Riverside Press. Retrieved from https://hdl.handle.net/2027/mdp.39015003348037

Ferguson, J. S. (1953). Agrarianism in Mississippi, 1871-1900: A study in nonconformity (Doctoral dissertation). University of North Carolina at Chapel Hill. Retrieved from ProQuest Dissertations \& Theses Global. (302050523).

Foner, N. (2000). Beyond the melting pot three decades later: Recent immigrants and New York's new ethnic mixture. International Migration Review, 34(1), 255-262. doi:10.2307/2676022

Glazer, N. (2000). Disaggregating Culture. In L. E. Harrison \& S. P. Huntington (Eds.), Culture matters: How values shape human progress. New York: Random Books.

Gloor, L. B. (2006). From the melting pot to the tossed salad metaphor: Why coercive assimilation lacks the flavors Americans crave. Hohonu: A Journal of Academic Writing, 4(2006), 29-32. University of Hawaii, Hilo. Retrieved from https://hilo.hawaii.edu/campuscenter/hohonu/volumes/documents/ Vol04x06FromtheMeltingPot.pdf

Huber, P. (1995). A short history of redneck: The fashioning of a southern white masculine identity. Southern Cultures, 1(2), 145-166. doi:10.1353/scu.1995.0074

Hui, B. P. H., Chen, S. X., Leung, C. M., \& Berry, J. W. (2015). Facilitating Adaptation and Intercultural Contact: The role of Integration and Multicultural Ideology in Dominant and Non-dominant Groups. International Journal of Intercultural Relations, 45(2015), 70-84. doi:10.1016/j.ijintrel.2015.01.002

"Joint Resolution Authorizing the President of the United States of America to Proclaim I Am An American Day, for the Recognition, Observance, and Commemoration of American citizenship" (Pub. Res., No. 67, May 3, 1940) 54 United States Statutes at Large, p. 178.

"Joint Resolution designating September 17 of each year as "Citizenship Day" (PL 82-261; H.J. Res. 314, February 29, 1952), 66 United States Statutes at Large, p. 9.

Jones, S. (1997). The archaeology of ethnicity: Constructing identities in the past and present. New York, NY: Routledge.

Kivisto, P. (2004). What is the canonical theory of assimilation? Journal of the History of the Behavioral Sciences, 40(2), 149-163. doi:10.1002/jhbs.20013

Korac, M. (2004). Living ethnicity in exile: Identity processes in refugees from former Yugoslavia'. In R. Saifert (Ed.), Gender, Identitaet und kriegerischer Konflikt. Das Beispiel des ehemaligen Jugoslawien; Muenster: Lit Verlag (pp.131- 151). Retrieved from http://hdl.handle.net/10552/672

Krishnan, A., \& Berry, J. W. (1992). Acculturative stress and acculturation attitudes among Indian immigrants to the United States, Psychology and Developing Societies, 4(2), 187-212. doi:10.1177/097133369200400206 
Kymlicka, W. (1995). Multicultural citizenship: A liberal theory of minority rights. Oxford: Clarendon Press.

Lafer, S., \& Tarman, B. (2019). Editorial 2019: (2)1, Special Issue. Journal of Culture and Values in Education, 2(1), i-v. Retrieved from http://cultureandvalues.org/index.php/JCV/article/view/34

Laubeova, L. (2005). Melting pot vs. ethnic stew. In C. Skutsch \& J. M. Ryle (Eds.), Encyclopedia of the world's minorities, (Vol. 2, pp. 808-809). Routledge: New York.

Lichter, D. T. (2013). Integration or fragmentation? Racial diversity and the American future. Demography, 50(2), 359-391. doi:10.1007/s13524-013-0197-1

López-Rodríguez, I. (2014). Are we what we eat? Food metaphors in the conceptualization of ethnic groups. Linguistik Online, 69(7), 3-36. doi:10.13092/lo.69.1655

Maher, J. (2005). Metroethnicity, language, and the principle of cool. International Journal of the Sociology of Language, 2005(175-176), 83-102. doi:10.1515/ijs1.2005.2005.175-176.83

Malkki, L. H. (1995). Purity and exile: Violence. memory, and national cosmology among Hutu refugees in Tanzania. Chicago, IL: University of Chicago Press.

Meier, L. (2019). Questioning the Problematic Nature of School Culture in Elementary Teacher Education. Journal of Culture and Values in Education,2(1), 34-44. Retrieved from http://cultureandvalues.org/index.php/JCV/article/view/30

Miller, D. (2005). Citizenship and national identity. Maldon, MA: Polity Press.

Moro, L. N. (2004). Interethnic relations in exile: The politics of ethnicity among Sudanese refugees in Uganda and Egypt. Journal of Refugee Studies, 17(4), 420-436. doi:10.1093/jrs/17.4.420

Nguyen, A-M. D., \& Benet-Martínez, V. (2013). Biculturalism and adjustment: A meta-analysis. Journal of Cross-Cultural Psychology, 44(1), 122-159. doi:10.1177/0022022111435097

"Oath of Renunciation and Allegiance," Title 8 United States Code. Sec. 1448. Retrieved from https://www.govinfo.gov/content/pkg/USCODE-2017-title8/pdf/USCODE-2017-title8-chap12subchapIII-partII-sec1448.pdf

Park, R. E. \& Burgess, E. W. (1924). Introduction to the science of sociology. Chicago, IL: The University of Chicago Press.

Pasetti, F. (2019). Configurations of immigrant integration policies in Europe: An exploratory appraisal. World Affairs, 182(1), 35-60.

Phinney, J. S., Horenezyk, G., Liebkind, K., \& Vedder, P. (2001). Ethnic identity, immigration, and wellbeing: An interactional perspective. Journal of Social Issues, 57(3), 493-510. doi:10.1111/0022-4537.00225

Pionkowski, U., Rohmann, A., \& Florack, A. (2002). Concordance of acculturation attitudes and perceived threat. Group Processes and Intergroup Relations, 5(3), 221-232. doi:10.1177/1368430202005003003

Shelby, A. (1999). The 'R' word: What's so funny (and not so funny) about redneck jokes. In D. B. Billings, G. Norman, \& K. Ledford (Eds.), Back talk from Appalachia: Confronting stereotypes. Kentucky: University Press of Kentucky.

St. John de Crevecoeur, H. (1782). What is an American. Letters from an American farmer: Letter III. Retrieved from http://avalon.law.yale.edu/18th_century/letter_03.asp

Swaidan, Z. (2018). Acculturation strategies of Asian-Americans. Competition Forum, 16(2), 39-45.

Tarman, B. \& Gürel, D. (2017). Awareness of Social Studies Teacher Candidates on Refugees in Turkey, Journal of Social Studies Research, DOI: 10.1016/j.jssr.2016.11.001

Tartakovsky, E. (2002). Acculturation attitudes of potential emigrants: Jewish youths in Russia. Journal of Applied Social Psychology, 32(9), 1845-1862. doi:10.1111/j.1559-1816.2002.tb00262.x

Thornton, B. (2012). Melting pots and salad bowls. Hoover Digest, 2012(4). Retrieved from https://www.hoover.org/research/melting-pots-and-salad-bowls

Wagener, A. (2009). In the melting pot: Integration, assimilation, and uniform societies. Institute of Social Policy Working Paper, University of Hannover, Germany. Retrieved from https://www.wipol.unihannover.de/fileadmin/wipol/publications/Wagener_In_the_Melting_Pot.pdf (accessed August 20, 2018).

Woofter, S. (2019). Book Review: Building Equity: Policies and Practices to Empower All Learners. American Journal of Qualitative Research, 3(1), 136-139. https://doi.org/10.29333/ajqr/5815

Zangwill, I. (1921). The Melting Pot. New York: American Jewish Book Company. Retrieved from: http://www.gutenberg.org/ebooks/23893 